\title{
Ultrastructural Analysis of the Distribution of Synaptic Boutons from Labeled Preganglionic Axons on Rabbit Ciliary Neurons
}

\author{
Cynthia J. Forehand \\ Department of Anatomy and Neurobiology, Washington University School of Medicine, St. Louis, Missouri 63110
}

The number of preganglionic inputs that innervate rabbit ciliary ganglion cells is directly correlated with the number of dendrites arising from each ganglion cell (Purves and Hume, 1981). In general, the innervation of multiply innervated ciliary neurons by individual preganglionic axons is regionally restricted to a portion of the postsynaptic surface that usually includes the cell body and some, but not all, of the dendrites (Forehand and Purves, 1984). These observations suggest that dendrites niodulate convergence to each cell by providing relatively separate postsynaptic domains for individual inputs. To examine this possibility further, 1 have assessed the distribution of synaptic boutons from individually labeled preganglionic axons on ciliary ganglion cells at the ultrastructural level.

The results show that at least a third of the dendrites of these neurons are contacted exclusively by synaptic boutons from a single preganglionic axon. However, at least half of the dendrites (and nearly all of the cell bodies) of multiply innervated ganglion cells are innervated by at least 2 different preganglionic axons. Moreover, synapses from 2 different inputs often coexist in close proximity on the postsynaptic surface. Thus, individual preganglionic axons do not require exclusive dominion over a particular part of a postsynaptic cell in order to maintain their connection with the cell. These results suggest that competitive interactions between the inputs to these cells occur between the sets of boutons arising from different inputs, rather than at the level of individual boutons. If separation of different inputs on the postsynaptic surface is the reason why the presence of dendrites increases convergence, the diminished interaction between different inputs must arise from an average separation of the sets of boutons elaborated by each axon.

The number of preganglionic axons that innervate autonomic ganglion cells is proportional to the dendritic complexity of the target neurons: cells that lack dendrites tend to have only one input, whereas the number of inputs increases as the number of dendrites increases (Purves and Hume, 1981; Purves and

\footnotetext{
Received Nov. 21, 1986; revised Mar. 18, 1987; accepted Apr. 10, 1987.

This work was supported by National Institutes of Health Grants NS 18629 and 11699 to D. Purves and was carried out during the tenure of a Postdoctoral Fellowship from the Muscular Dystrophy Association. Excellent technical assistance was provided by P. Newton and D. Dill. I thank Dr. D. Purves for support and advice during the course of this project, and R. Hadley, J. Lichtman, J. Sanes, W. Snider, and J. Voyvodic for comments on the manuscript.

Correspondence should be addressed to Cynthia J. Forehand, Department of Anatomy and Neurobiology 8108, Washington University School of Medicine, 660 South Euclid, St. Louis, Missouri 63110.

Copyright (C) 1987 Society for Neuroscience $0270-6474 / 87 / 103274-08 \$ 02.00 / 0$
}

Lichtman, 1985; Snider, 1986, 1987). A possible explanation of the relation between convergence and dendritic morphology is that individual dendrites provide relatively separate spatial domains for different inputs to these ganglion cells (see Purves and Hume, 1981; Hume and Purves, 1983; Forehand and Purves, 1984). In the rabbit ciliary ganglion, the innervation of geometrically complex - and thus multiply innervated-neurons by individual preganglionic axons is regionally restricted. The contacts made by an individual preganglionic axon onto such neurons are limited to a portion of the postsynaptic surface that usually includes the cell body and some, but not all, of the dendrites (Forehand and Purves, 1984). The degree to which the presence of terminals from one input on a particular region of a postsynaptic cell's surface excludes other inputs to that region is not known.

To address this issue, I have examined the innervation of rabbit ciliary ganglion cells at the ultrastructural level; in particular, I have looked at the distribution of synaptic boutons from individually labeled preganglionic axons on the surface of their target cells. The main point I have addressed is whether dendrites that receive synapses from a labeled preganglionic axon are also innervated by unlabeled synapses. In other words, to what degree are the different inputs to a multiply innervated ganglion cell segregated from each other on the cell soma and dendrites?

The results show that about half of the dendrites (and nearly all of the somata) of multiply innervated cells receive innervation from at least 2 preganglionic inputs. On the other hand, at least $30 \%$ of the dendrites examined were exclusively innervated by a single input. (Whether the remaining $20 \%$ of the dendrites were singly or multiply innervated could not be determined.) Examination of multiply innervated dendrites showed that synaptic boutons from different inputs to a target cell can coexist in close proximity. Thus, the presence of dendrites does not preclude considerable mingling of inputs on the postsynaptic surface. Accordingly, the mechanism that promotes multiple innervation on complex ganglion cells must depend on an interaction between the sets of boutons arising from different preganglionic inputs, rather than interactions at the level of single boutons.

Some of these results have been reported in abstract form (Forehand and Dill, 1984).

\section{Materials and Methods}

HRP labeling of preganglionic axons. Adult rabbits were anesthetized by intravenous injection of pentobarbital and perfused through the heart with oxygenated mammalian Ringer's fluid. The left ciliary ganglion was removed and placed in a Plexiglas chamber superfused with oxygenated Ringer's at room temperature; the pre- and postganglionic nerves 

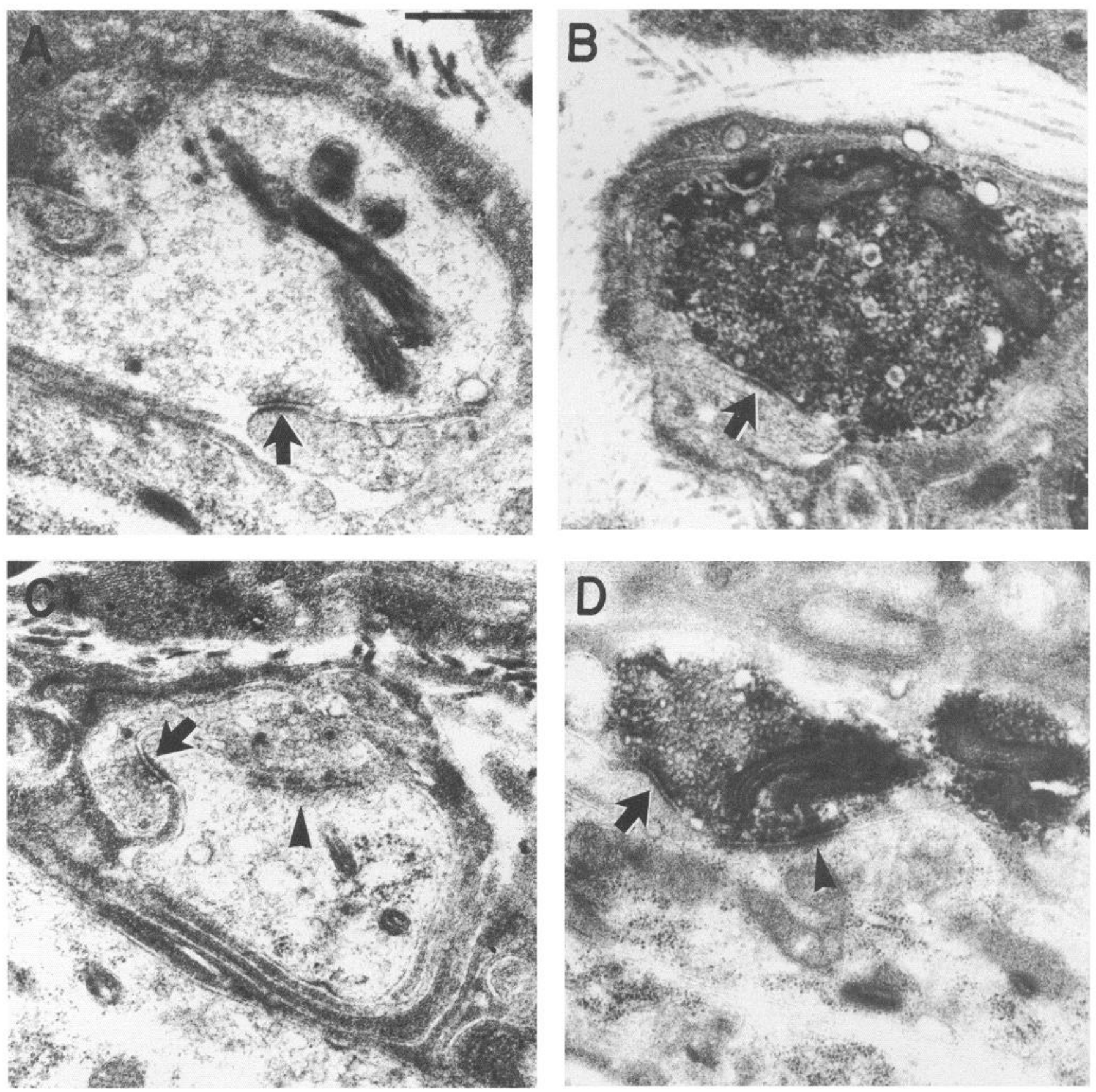

Figure 1. Morphology of unlabeled $(A$ and $C)$ and HRP-labeled $(B$ and $D)$ synaptic boutons in the ciliary ganglion of the rabbit. Synaptic active zones with a presynaptic accumulation of synaptic vesicles apposed to a postsynaptic density are apparent in both labeled and unlabeled synaptic boutons (arrows in $A-D$ ). In addition to synaptic active zones, cell-cell adhesions known as puncta adherentes often form between a bouton and the postsynaptic cell; the puncta adherentes are readily distinguished from synaptic active zones by their lack of an accumulation of synaptic vesicles and the relatively symmetrical membrane specializations on either side of the junction (arrowheads in $C$ and $D$ ). (These junctions are not synapse specific; they are often seen between 2 dendrites and between a dendrite and cell soma.) Scale bar, $0.5 \mu \mathrm{m}$.

were drawn into suction electrodes for stimulation and recording, respectively (see Johnson and Purves, 1981, for details). Intracellular recordings were obtained with microelectrodes pulled from triangular glass (Glass Co. of America) and filled with 5\% HRP (Sigma, type VI) in 0.2 $\mathrm{M}$ potassium acetate buffered to $\mathrm{pH} 7.6(120-200 \mathrm{M} \Omega)$. Preganglionic axons were identified by characteristic electrophysiological criteria (Hume and Purves, 1983) and subsequently filled with HRP by iontophoresis (50 msec, 3-5 nA depolarizing pulses at $5 \mathrm{~Hz}$ for $10 \mathrm{~min}$ ). As many axons as could be impaled within 2-3 hr were filled; a further hour was then allowed for the HRP to spread through the injected axons. Generally, axons were impaled at the base of the ganglion close to the preganglionic nerve. The success rate of filling preganglionic axons is low (Hume and Purves, 1983; Forehand and Purves, 1984); typically, 3-5 axons were injected, and one of these was successfully filled. A total of 15 ganglia in as many animals were used for the study.

Histological processing and electron microscopy. Ganglia were fixed overnight in $1.25 \%$ glutaraldehyde and $0.5 \%$ paraformaldehyde in HEPES buffer $\left(\mathrm{pH} 7.6\right.$ at $\left.4^{\circ} \mathrm{C}\right)$. They were then rinsed in the buffer, embedded in rapidly fixed gelatin-albumin (Bowers and Zigmond, 1979), and sectioned serially at $40 \mu \mathrm{m}$ on a vibratome. The HRP reaction product was developed using diaminobenzidine as the substrate (Graham and Karnovsky, 1966). Individual $40 \mu \mathrm{m}$ sections were examined in wet mounts at $400 \times$, and those sections containing label were processed for electron microscopy. The sections were equilibrated in $0.1 \mathrm{M}$ cacodylate 


\begin{tabular}{|c|c|c|c|c|c|c|}
\hline \multirow[b]{2}{*}{ Cell } & \multirow{2}{*}{$\begin{array}{l}\text { Minimum } \\
\text { no. of } \\
\text { dendrites }^{\alpha}\end{array}$} & \multirow{2}{*}{$\begin{array}{l}\text { Minimum } \\
\text { no. of } \\
\text { inputs }^{b}\end{array}$} & \multirow{2}{*}{$\begin{array}{l}\text { Somatic } \\
\text { innervation }\end{array}$} & \multicolumn{3}{|c|}{ Dendritic innervation } \\
\hline & & & & D1 & D2 & D3 \\
\hline 1 & 0 & 1 & Labeled & & & \\
\hline 2 & 0 & 1 & Labeled & & & \\
\hline 3 & 0 & 1 & Labeled & & & \\
\hline 4 & 0 & 2 & Mixed & & & \\
\hline 5 & 1 & 1 & Labeled & Labeled & & \\
\hline 6 & 1 & 1 & Labeled & Labeled & & \\
\hline 7 & 1 & 1 & Labeled & Labeled & & \\
\hline 8 & 1 & 1 & Laheled & Labeled & & \\
\hline 9 & 1 & 1 & Labeled & Labeled & & \\
\hline 10 & 1 & 1 & Labeled & Labeled & & \\
\hline 11 & 1 & 1 & Labeled & Labeled & & \\
\hline 12 & 1 & 1 & Labeled & Labeled & & \\
\hline 13 & 1 & 2 & Mixed & Labeled & & \\
\hline 14 & 1 & 2 & Mixed & Mixed & & \\
\hline 15 & 1 & 2 & Mixed & Mixed & & \\
\hline 16 & 1 & 2 & Mixed & Mixed & & \\
\hline 17 & 1 & 2 & Mixed & Mixed & & \\
\hline 18 & 2 & 2 & Mixed & Mixed & Labeled & \\
\hline 19 & 2 & 2 & Mixed & Mixed & Labeled & \\
\hline 20 & 2 & 2 & Mixed & Mixed & Labeled & \\
\hline 21 & 2 & 2 & Mixed & Mixed & Labeled & \\
\hline 22 & 2 & 2 & Mixcd & Mixcd & Unlabcled & \\
\hline 23 & 2 & 2 & Mixed & Mixed & Unlabeled & \\
\hline 24 & 2 & 2 & Mixed & Mixed & Unlabeled & \\
\hline 25 & 2 & 2 & Mixed & Labeled & Unlabeled & \\
\hline 26 & 2 & 2 & Mixed & Labeled & Unlabeled & \\
\hline 27 & 2 & 2 & Unlabeled & Mixed & Unlabeled & \\
\hline 28 & 2 & 2 & Labeled & Mixed & Labeled & \\
\hline 29 & 2 & 2 & Labeled & Labeled & Unlabeled & \\
\hline 30 & 3 & 2 & Labeled & Mixed & Mixed & Labeled \\
\hline
\end{tabular}

${ }^{a}$ Determined by partial reconstruction of the cell.

tLabeled synapses represent only 1 input, but unlabeled synapses could be one or more inputs; thus, 2 is the maximum number of differentiable inputs.

buffer, postfixed in $1 \%$ osmium tetroxide in cacodylate buffer for 30 min, rinsed, and dehydrated through graded alcohol solutions. The sections were wafer-embedded in Araldite using propylene oxide as the transition solvent. Embedded sections were again cxamined at $400 \times$, and all labeled elements were drawn with the aid of a camera lucida to facilitate electron microscopic reconstruction of the label. Serial thin sections were then obtained and stained with lead citrate and uranyl acetate.

Unlabeled ganglion cells that received synapses from an HRP-labeled axon were identified and followed through serial sections to determine the number of dendrites arising from each cell. A process was assumed to be a dendrite if it extended at least a cell body diameter away from the soma and contained the characteristic organelles of dendrites (microtubules, ribosome rosettes). Cells that had at least one dendrite, and received both labeled and unlabeled synapses, were examined in detail to determine the distribution of boutons from the labeled axon on the soma and dendrite(s) with respect to at least one other input to the cell. The phrase "synaptic bouton" in what follows refers to a vesicle-filled swelling that arises from a preganglionic axon and contains at least one active zone consisting of a cluster of synaptic vesicles adjacent to the presynaptic membrane and directly opposite a postsynaptic membrane specialization (Fig. 1). Individual dendrites were typically followed for 20-150 $\mu \mathrm{m}$ outward from the cell. Portions of the dendrites were reconstructed from photomicrographs, and the lengths of these segments determined with the aid of a digitizing tablet, computer, and locally written software (Voyvodic, 1986). These measurements of dendritic lengths made from photomicrographs included only $50 \%$ or less of the total length examined for each dendrite.

Since unlabeled synapses could be derived from more than one input, only 2 separate inputs to a particular ganglion cell could be distinguished in this study. Thus, the degree of mixing of synapses from different inputs along postsynaptic structures is likely to be somewhat greater than that observed here. This bias is probably not very great since the average number of inputs to ciliary ganglion cells in the rabbit is only 2.2 (Johnson and Purves, 1981).

Unlabeled synapses might arise from branches of labeled axons that were not entirely filled with HRP; however, labeled axons followed at the ultrastructural level never gave rise to unlabeled branches. Thus, most, if not all, branches of an injected axon become filled with HRP. Moreover, in some instances the preterminal axon branch from which an unlabeled synapse arose could be followed back to its parent axon; in these cases, the parent axons were also unlabeled (see Fig. 4).

\section{Results}

Thirty ciliary ganglion cells that received innervation from individually labeled preganglionic axons were examined (Table 1). Eleven of these 30 cells received only labeled synapses and were thus innervated by only a single preganglionic axon. These 


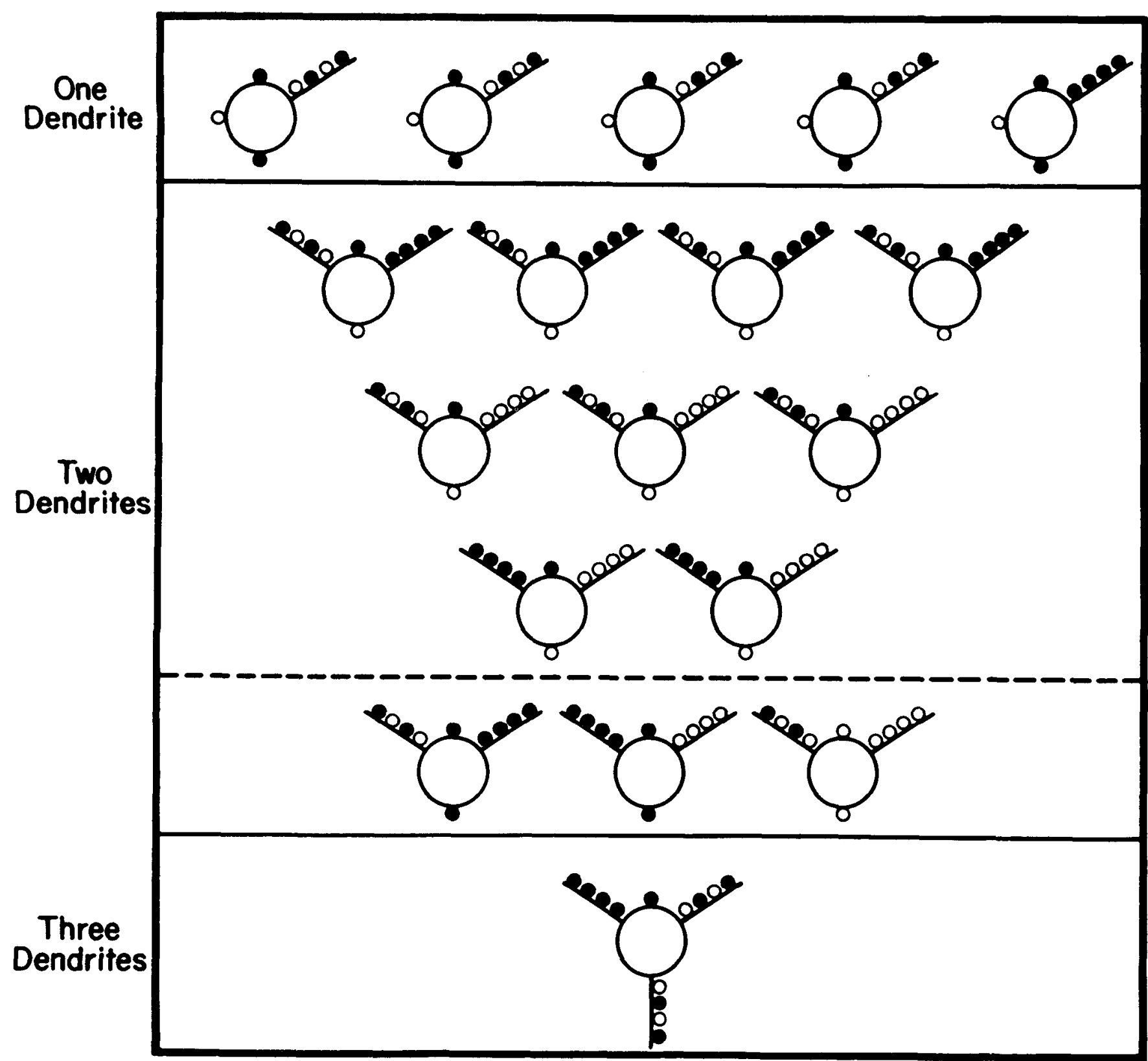

Figure 2. Diagrammatic representation of the innervation of the 18 cells examined that had at least one dendrite and were innervated by at least 2 inputs. Filled circles indicate innervation by an HRP-labeled preganglionic axon; open circles represent innervation by one (or more) unlabeled preganglionic axons. The innervation of the cell body and each of the dendrites is indicated as labeled, unlabeled, or mixed (labeled and unlabeled). Where there is mixed input, the proportion of labeled and unlabeled innervation is arbitrarily shown as equal. Groups of cells with different numbers of dendrites are separated by solid lines. All of the cells above the dotted line had mixed input to their somata.

cells were excluded from further analysis since they could provide no information with respect to how different inputs to the same cell are distributed. Similarly, another cell that was innervated by 2 inputs but had no dendrites was also excluded. The remaining 18 cells received both labeled and unlabeled synaptic boutons and had at least one dendrite. These 18 cells were examined in detail to determine whether different inputs to the same cell are segregated from each other on the cell soma and dendrites. The distribution of innervation on these cells is shown diagrammatically in Figure 2 . The remainder of the results concern these neurons.

\section{Innervation of neuronal somata}

Three of the 18 cells with at least one dendrite that were innervated by at least 2 inputs received only labeled synapses on their somata; one cell had only unlabeled synapses on the soma (Fig. 2). The remaining 14 cells had both labeled and unlabeled somatic synapses (Fig. 2). This finding is consistent with the light microscopic obscrvation that rabbit ciliary neurons usually receive somatic innervation from each of their preganglionic inputs (Forehand and Purves, 1984). Thus, the cell bodies of multiply innervated ganglion cells generally receive synapses 
Figure 3. Distribution of synaptic boutons along selected portions of 13 of the 15 dendrites that were innervated by at least 2 different inputs. Each row represents a contiguous stretch of a different dendrite contacted by at least 3 synaptic boutons; the length of each segment is indicated at left. (The total length examined for each of these dendrites was considerably longer than that shown; the sample is limited to those portions of the dendrites that were examined in their entirety and received at least 3 synapses.) The linear arrangement of labeled (filled circles) and unlabeled (open circles) boutons along the dendrites is shown; the spacing between boutons is arbitrarily equidistant. The presence of labeled and unlabeled synapses along each of these stretches indicates that when multiple innervation of a dendrite occurs there is no segregation of the boutons from different inputs along the postsynaptic surface. Inset, Neighbor relationship between labeled and unlabeled boutons. The percentage of times a bouton is the same as or different from its neighbor to the right is indicated. The data represent a total of 59 synapses along $295.5 \mu \mathrm{m}$ of dendrites. The density of synapses here ( 1 bouton $/ 5$ $\mu \mathrm{m})$ is similar to that for all photographed segments of dendrites in this study ( 240 synapses in $1479 \mu \mathrm{m}$, or 1 bouton $/ 6 \mu \mathrm{m})$. These values are also similar to the density of dendritic synapses on rat superior cervical ganglion cells [on average, 1 synapse $/ 5 \mu \mathrm{m}$; this density is derived from a total dendritic length of $1701 \mu \mathrm{m}$ (Purves and Lichtman, 1984) over which 319 synapses were distributed (Forehand, 1985)].
A

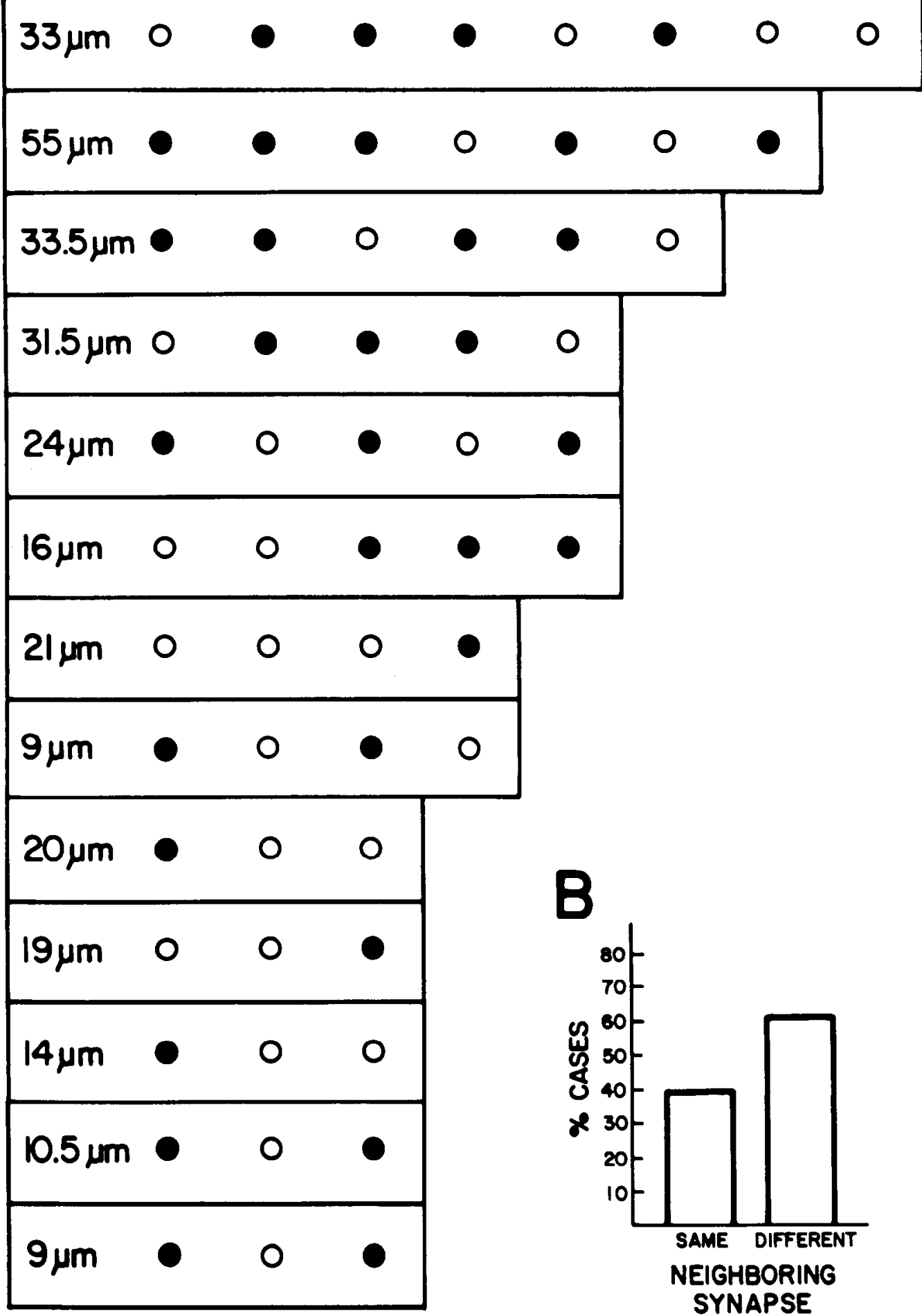

from more than one input. (The axons of ganglion cells are, in general, not innervated except near their site of origin; see also Forehand and Purves, 1984.)

\section{Innervation of dendrites}

Individual dendrites were followed outward from the cell body and photographs for detailed analysis wcre taken of about half of the overall length observed in serial sections; the photo- graphed stretches ranged from 6 to $82 \mu \mathrm{m}$ (mean, $30 \mu \mathrm{m}$ ). On average, the length of individual dendrites is $140 \mu \mathrm{m}$ for cells with a single dendrite, and $165 \mu \mathrm{m}$ for cells with 2 dendrites (Purves and Hume, 1981). Thus, the full length I examined averaged $40 \%$ of the total length of a typical dendrite; the length photographed for more detailed analysis represented about $20 \%$ of the length of an average dendrite.

Ten of the 32 dendrites examined received only labeled syn- 

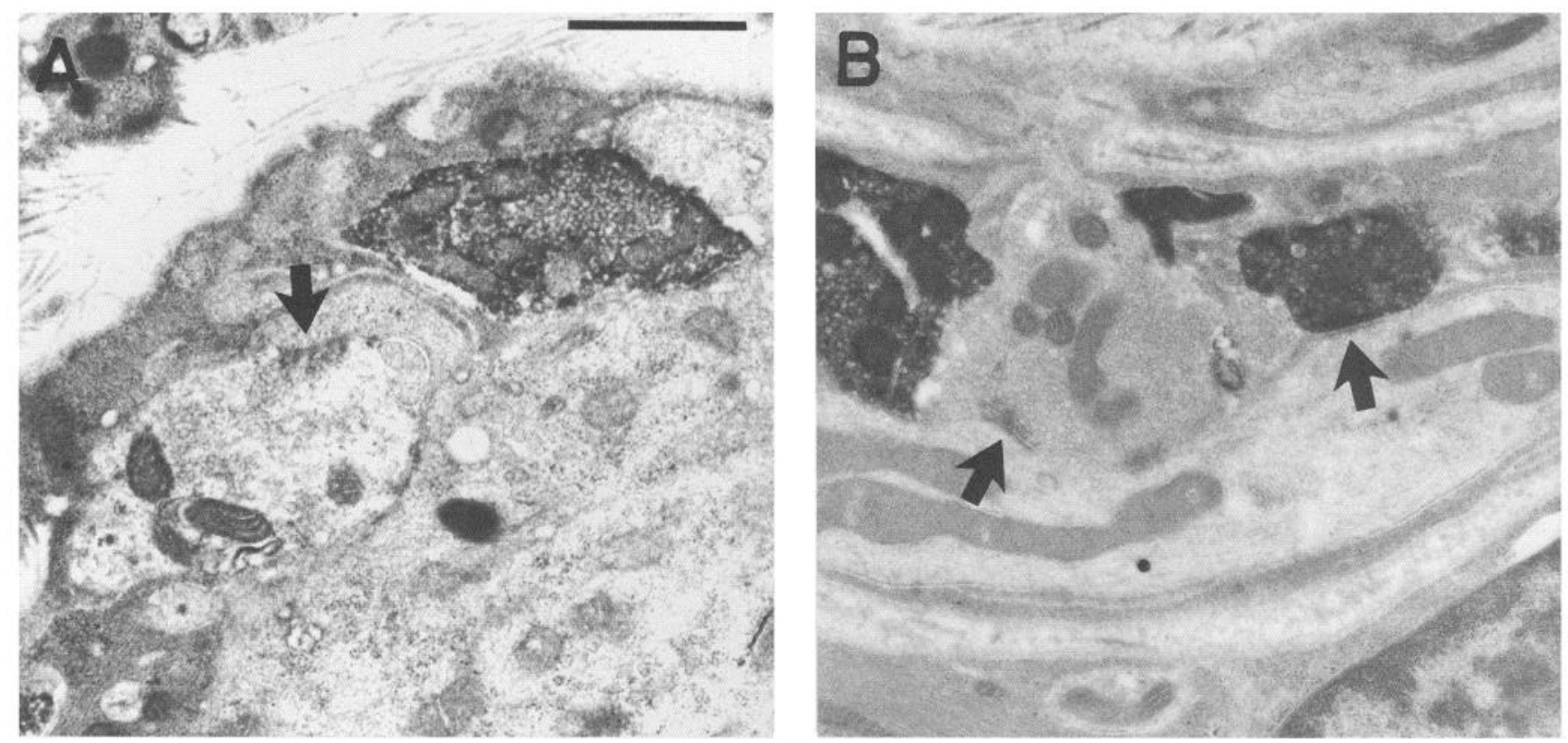

Figure 4. Electron micrographs of labeled and unlabeled synaptic boutons on a ciliary ganglion cell body $(A)$ and dendrite $(B)$. A synaptic active zone is apparent between the unlabeled bouton and an extension from the cell body in $A$ (arrow); the active zone for the labeled bouton in $A$ is not present in this $0.1 \mu \mathrm{m}$ section through the bouton. In $B$, an active zone is present in the unlabeled bouton and in one of the labeled boutons (arrows). HRP-labeled synaptic boutons derive from an individual preganglionic axon that was filled intracellularly with HRP, while unlabeled boutons derive from one or more additional inputs to the same cell. The preterminal axon from which the unlabeled synapse in $B$ derived was followed through serial sections to its parent axon, which was not labeled; thus, unlabeled synapses scattered among labeled synapses do not result from branches of a labeled parent axon that failed to fill with HRP. Scale bar, $1 \mu \mathrm{m}$.

apses. Because the entire length of the dendrites was not examined, the possibility remains that a given dendrite was also innervated by unlabeled boutons at some more distal point. However, this possibility is unlikely since preganglionic axons generally follow the dendrites they innervate out from the cell body to the tip of the dendrite (Forehand and Purves, 1984). Seven of the 32 dendrites received only unlabeled synapses; however, since these cases might have represented innervation by more than one input, they contribute little further information.

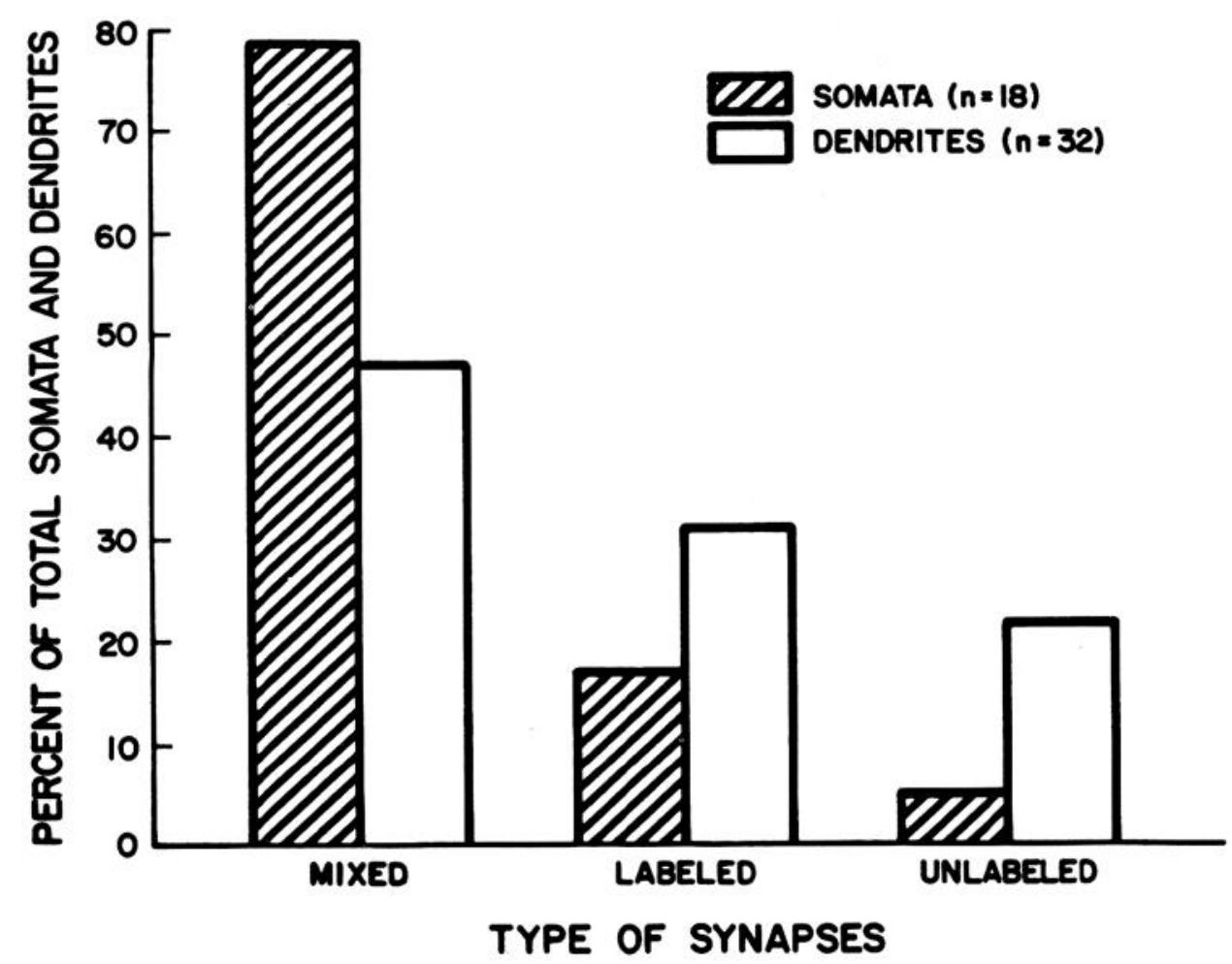

Figure 5. Synaptic distribution on cell bodies and dendrites of ciliary ganglion cells with at least 2 inputs and at least 1 dendrite. The percentages of cell somata and dendrites that received mixed (labeled and unlabeled), labeled, or unlabeled synaptic inputs are shown. Labeled synapses derive from a preganglionic axon that was intracellularly filled with HRP; unlabeled synapses derive from one or more additional inputs to the cell. 


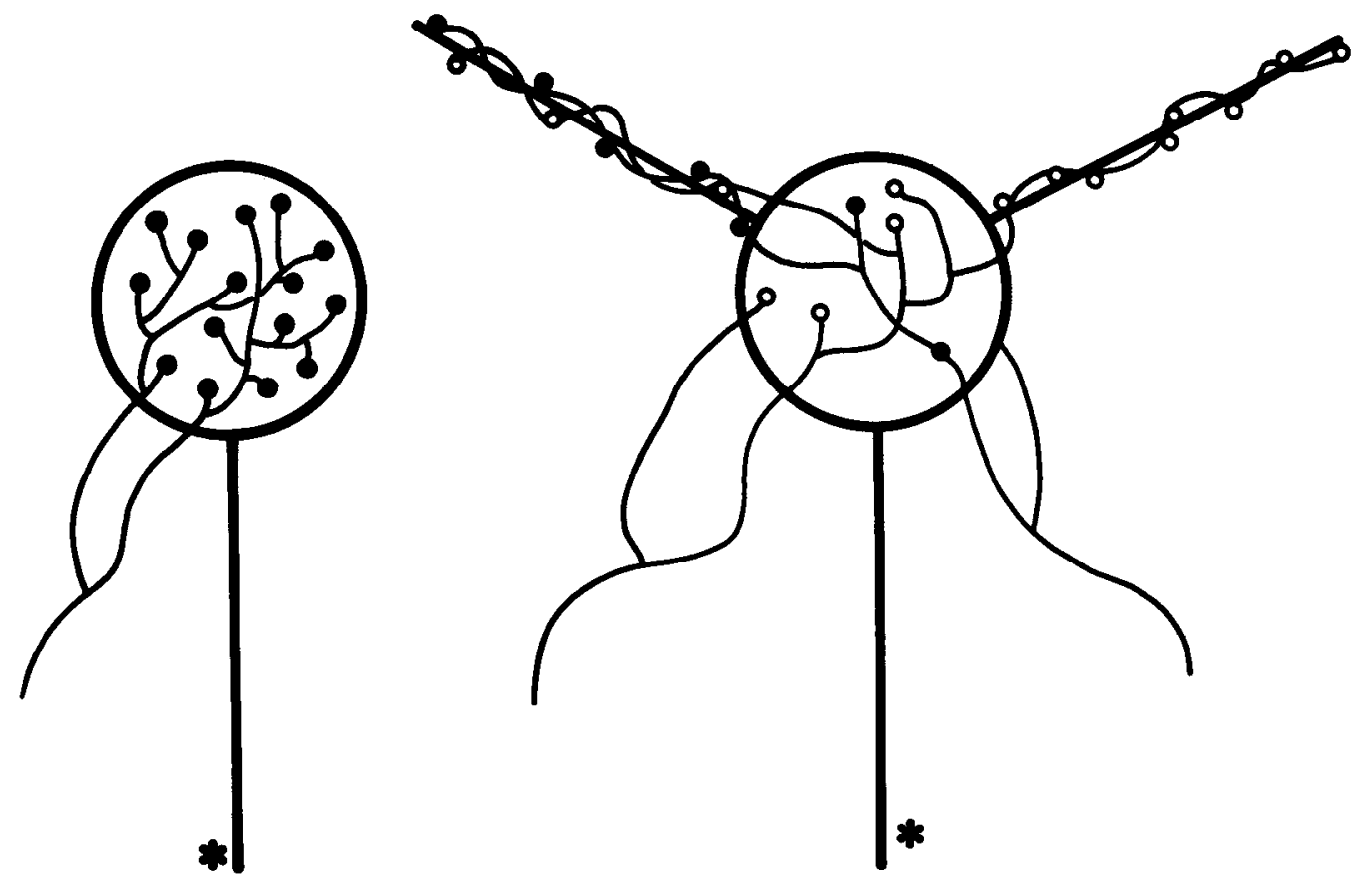

Figure 6. Diagram of 2 autonomic ganglion cells showing the general pattern of innervation on neurons with and without dendrites. Ganglion cell axons are marked by the asterisks. The synaptic boutons from 2 different preganglionic axons are represented by filled and open circles. See text for explanation.

Fifteen of the 32 dendrites examined were contacted by both labeled and unlabeled synapses and were thus innervated by at least 2 preganglionic axons (Fig. 2). In none of these cases were the boutons from different inputs segregated in any obvious way along the dendritic surface (Fig. 3). It is not the case, therefore, that all of the boutons from one input are made on one part of the dendrite, while those from another input are elsewhere on the dendrite. In fact, labeled and unlabeled boutons often coexist in close proximity on both cell bodies and dendrites (Fig. 4).

The degrce of mixing of synapses from 2 different inputs on dendrites is considerably less than on somata. Seventy-eight percent of the somata of ganglion cells with at least 2 inputs and one dendrite received mixed synapses, whereas only $47 \%$ of the dendrites received both labeled and unlabeled synapses (Fig. 5).

\section{Discussion}

This investigation extends previous light and electron microscopic observations on the innervation of rabbit ciliary ganglion cells by asking how different inputs to the same cell are distributed with respect to one another. A summary of the pattern of innervation of these neurons is diagrammed in Figure 6. This figure emphasizes several points: (1) Ganglion cells without dendrites receive many somatic synapses, all of which are usually derived from a single preganglionic axon. (2) The number of preganglionic inputs increases with the number of ganglion cell dendrites. (3) As a rule, each of the inputs to a ganglion cell innervates the cell body. (However, the total number of synapses on the cell body decreases as the number of separate inputs increases; see Hume and Purves, 1983; Forehand, 1985.) (4) Some ganglion cell dendrites are exclusively innervated by a single preganglionic axon, but some are innervated by 2 or more preganglionic axons. (5) Individual synaptic boutons from 2 separate inputs often coexist in close proximity on either the somatic or dendritic surface.
The correlation between preganglionic convergence and target cell morphology in autonomic ganglia is apparently determined by the postsynaptic cell: the number of dendrites regulates the number of inputs. Thus, the adult number of inputs is established in postnatal life through a competitive elimination of an initial excess number of inputs (Lichtman, 1977; Johnson and Purves, 1981; Lichtman and Purves, 1981; Snider, 1986), whereas the number of primary dendrites at birth is similar to the adult value (Hume and Purves, 1981; Voyvodic and Purves, 1984; Snider, 1986; Voyvodic, 1987).

Several mechanisms might explain why dendrites allow more convergence onto ganglion cells. One possibility is that dendrites simply provide more synaptic space and in this way tend to support multiple inputs. While this explanation may have some merit, it cannot account for the fact that individual preganglionic neurons increase the number of synapses they make on some cells while losing their connections with other cells entirely (Lichtman, 1977; Johnson and Purves, 1981; Purves and Hume, 1981). Moreover, the fact that the synapses made by individual preganglionic axons on ganglion cells are regionally restricted to the cell body, and only 1 or 2 of several dendrites (Forehand and Purves, 1984), argues that the importance of dendrites is more subtle than simply providing more synaptic space.

Another explanation of the way that dendrites might promote convergence onto ganglion cells is that dendrites (and the cell body) provide relatively separate spatial domains for each of the inputs, so that competitive interactions between the inputs are reduced (Purves and Hume, 1981). Indeed, previous investigations provide circumstantial evidence for this idea (Hume and Purves, 1983; Forehand and Purves, 1984). Perhaps the major importance of the results reported here is the way in which they extend and qualify this view. First, while some dendrites are innervated predominantly by a single preganglionic axon, many dendrites share at least 2 preganglionic inputs (Figs. 2, 3, 
5). Thus, dendrites do not, as a rule, provide exclusive postsynaptic domains for different inputs. Moreover, the synapses from different preganglionic axons need not be spatially separate from each other: Labeled and unlabeled boutons are often observed in close approximation (Fig. 3). This observation underscores the idea that axonal interactions on the postsynaptic cell concern the terminals from individual axons acting as sets, rather than individually (see also Lichtman, 1977; Purves and Lichtman, 1980; Purves, 1983; Sargent, 1983).

The information presently available suggests the following view of the way dendrites regulate the number of inputs received by autonomic ganglion cells. During development, innervation occurs initially on the cell somata, before dendrites are extended (Rubin, 1985); most synaptogenesis then occurs concurrently with the major phase of dendritic growth (Smolen and Raisman, 1980; Smolen and Beaston-Wimmer, 1986; Snider, 1986; Voyvodic, 1987). As dendrites grow out, synapses are apparently made on these processes in preference to the cell body (Hume and Purves, 1983; Forehand, 1985; Rubin, 1985). This increase in synaptic space provided by growing dendrites is not equally available to the different inputs: Each different axon innervates only 1 or 2 of a ganglion cell's dendrites (Forehand and Purves, 1984). As a result, the presence of dendrites causes the sets of terminals from individual inputs to be separated from one another. This average spatial separation of the boutons from different inputs on the surface of the target cell may then mitigate competitive interactions among the different inputs to the cell, perhaps by a mechanism related to the way in which trophic support is provided to the presynaptic terminals. The results reported here indicate that this mechanism operates in a fashion that permits considerable intermingling of the synapses from separate inputs on the postsynaptic surface.

The implication that competitive interactions between inputs to a particular target cell occur according to interactions between the sets of synapses arising from different axons, rather than at the level of individual boutons, excludes at least some of the possible mechanisms by which competitive interactions may operate. These results are likely to apply to other situations in which qualitatively similar inputs compete for particular target cells (Jackson and Parks, 1982), and perhaps to situations involving competition between qualitatively different inputs (see, for example, Garraghty et al., 1986).

\section{References}

Bowers, C. W., and R. E. Zigmond (1979) Localization of neurons in the rat superior cervical ganglion that project into different postganglionic trunks. J. Comp. Neurol. 185: 381-392.

Forehand, C. J. (1985) Density of somatic innervation on mammalian autonomic ganglion cells is inversely related to dendritic complexity and preganglionic convergence. J. Neurosci. 5: 3403-3408.

Forehand, C. J., and D. Dill (1984) Innervation of rabbit ciliary neurons: Electron microscopic analysis of the distribution of synaptic boutons from horseradish peroxidase-labeled preganglionic neurons. Soc. Neurosci. Abstr. 10: 1082.

Forehand, C. J., and D. Purves (1984) Regional innervation of rabbit ciliary ganglion cells by the terminals of preganglionic axons. J. Neurosci. 4: $1-12$.

Garraghty, P. E., M. Sur, and S. M. Sherman (1986) Role of competitive interactions in the postnatal development of $X$ and $Y$ retinogeniculate axons. J. Comp. Neurol. 251: 216-239.

Graham, R. C., Jr., and M. J. Karnovsky (1966) The early stages of absorbtion of injected horseradish peroxidase in the proximal tubules of the mouse kidney, ultrastructural cytochemistry by a new technique. J. Histochem. Cytochem. 14: 291-302.

Hume, R. I., and D. Purves (1981) Geometry of neonatal neurones and the regulation of synapse elimination. Nature 293: 469-471.

Hume, R. I., and D. Purves (1983) Apportionment of the terminals from single preganglionic axons to target neurons in the rabbit ciliary ganglion. J. Physiol. (Lond.) 338: 259-275.

Jackson, H., and T. N. Parks (1982) Functional synapse elimination in the developing avian cochlear nucleus with simultaneous reduction in cochlear nerve axon branching. J. Neurosci. 2: 1736-1743.

Johnson, D. A., and D. Purves (1981) Post-natal reduction of neural unit size in the rabbit ciliary ganglion. J. Physiol. (Lond.) 318: 143159.

Lichtman, J. W. (1977) The reorganization of synaptic connexions in the rat submandibular ganglion during post-natal development. J. Physiol. (Lond.) 273: 155-177.

Lichtman, J. W., and D. Purves (1981) The elimination of redundant preganglionic innervation to hamster sympathetic ganglion cells in early post-natal life. J. Physiol. (Lond.) 301: 213-228.

Purves, D. (1983) Modulation of neuronal competition by post-synaptic geometry in autonomic ganglia. TINS 6: 1-6.

Purves, D., and R. I. Hume (1981) The relation of postsynaptic geometry to the number of presynaptic axons that innervate autonomic ganglion cells. J. Neurosci. 1: 441-452.

Purves, D., and J. W. Lichtman (1980) Elimination of synapses in the developing nervous system. Science 210: 153-157.

Purves, D., and J. W. Lichtman (1984) Principles of Neural Development, Sinauer, Sunderland, MA.

Purves, D., and J. W. Lichtman (1985) Geometrical differences among homologous neurons in mammals. Science 228: 298-302.

Purves, D., E. Rubin, W. D. Snider, and J. Lichtman (1986) Relation of animal size to convergence, divergence and neuronal number in peripheral sympathetic pathways. J. Neurosci. 6: 158-163.

Rubin, E. (1985) Development of the rat superior cervical ganglion: Initial stages of synapse formation. J. Neurosci. 5: 697-704.

Sargent, P. B. (1983) The number of synaptic boutons terminating on Xenopus cardiac ganglion cells is directly correlated with cell size. J. Physiol. (Lond.) 343: 85-104.

Smolen, A. J., and P. Beaston-Wimmer (1986) Dendritic development in the rat superior cervical ganglion. Dev. Brain Res. 29: 245-252.

Smolen, A., and G. Raisman (1980) Synapse formation in the rat superior cervical ganglion during normal development and after deafferentation. Brain Res. 181: 315-323.

Snider, W. D. (1986) Rostrocaudal differences in dendritic growth and synaptogenesis in rat sympathetic chain ganglia. J. Comp. Neurol. 244: 245-253.

Snider, W. D. (1987) The dendritic complexity and innervation of submandibular neurons in five species of mammals. J. Neurosci. 7: $1760-1768$.

Voyvodic, J. T. (1986) A general purpose image processing language (IMAGR) facilitates visualizing neuronal structures in fixed tissue and in vivo. Soc. Neurosci. Abstr. 12: 390.

Voyvodic, J. (1987) Development and regulation of dendrites in the rat superior cervical ganglion: Influence of preganglionic innervation. J. Neurosci. 7: 904-912.

Voyvodic, J., and D. Purves (1984) Effect of denervation on dendritic growth in the neonatal superior cervical ganglion. Soc. Neurosci. Abstr. 10: 1082 . 